\title{
Lattice and Grain Boundary Diffusion \\ of Copper in $y$-Iron*
}

\author{
By Kazuhiko Majima**, and Hiroyasu Mitani**
}

\begin{abstract}
The lattice diffusion and the grain boundary diffusion of copper in $\gamma$-iron were measured in the temperature range from 1105 to $1210^{\circ} \mathrm{C}$ by the residual activity method with radio-active tracer ${ }^{64} \mathrm{Cu}$. The experimental penetration profiles were analysed by the instantaneous source model of grain boundary diffusion proposed by Suzuoka. The temperature dependence of the lattice diffusion coefficient $D_{\ell}$ and the grain boundary diffusion coefficient $D_{g b}$ are expressed by the following equations:

$$
\begin{gathered}
D_{\ell}=4.16 \times 10^{-4} \exp \left(-305.0 \mathrm{~kJ} \cdot \mathrm{mol}^{-1} / R T\right) \mathrm{m}^{2} \mathrm{~s}^{-1} \\
D_{g b} \cdot \delta=4.27 \times 10^{-13} \exp \left(-167.8 \mathrm{~kJ} \cdot \mathrm{mol}^{-1} / R T\right) \mathrm{m}^{3} \mathrm{~s}^{-1} \\
\text { (Received June 8, 1978) }
\end{gathered}
$$
\end{abstract}

\section{Introduction}

$\mathrm{Fe}-\mathrm{Cu}$ binary sintered compacts containing $3-25 \mathrm{wt} \% \mathrm{Cu}$ are widely used as the mechanical parts, and many papers ${ }^{(1)}$ have been published on the sintering mechanism of $\mathrm{Fe}-\mathrm{Cu}$ binary mixed powder compacts and sintering methods for the improvement of the mechanical properties. According to these papers, it has been confirmed that the $\mathrm{Fe}-\mathrm{Cu}$ binary mixed powder compacts expand abruptly at about $1083^{\circ} \mathrm{C}$ due to $\mathrm{Cu}$ melting, and this expansion (swelling) is an obstacle to the sintering of the compacts.

In order to clarify the cause of the abovementioned anomalous expansion, it is desired to determine the diffusion coefficient of $\mathrm{Cu}$ into $\gamma-\mathrm{Fe}$ at above $1083^{\circ} \mathrm{C}$. At present, there are a few reports ${ }^{(2) \sim(7)}$ about the $\mathrm{Cu}$ diffusion into $\gamma-\mathrm{Fe}$ at below $1083^{\circ} \mathrm{C}$, or into $\alpha-\mathrm{Fe}$. Above the temperature range there is only one report by Rothman $^{(8)}$ whose measurement, however, was in the temperature range above $1283^{\circ} \mathrm{C}$ where the effect of boundary diffusion is almost negligible. No reports have been published in the temperature range from $1083^{\circ} \mathrm{C}$ of $\mathrm{Cu}$ melting to $1250^{\circ} \mathrm{C}$ where the boundary diffusion is effective.

In this experiment, the lattice diffusion and the grain boundary diffusion of copper in $\gamma$ -

* This paper was originally published in Japanese in J. Japan Inst. Metals, 41 (1977), 1207.

** Department of Materials Science, Faculty of Engineering, Osaka University, Suita 565, Japan.

Trans. JIM iron were measured in the temperature range from 1105 to $1210^{\circ} \mathrm{C}$ using radioactive tracer ${ }^{64} \mathrm{Cu}$, and the data were analysed by the theory of grain boundary diffusion based on the instantaneous source model proposed by Suzuoka ${ }^{(9) \sim(11)}$.

\section{Experimental Procedure}

Iron specimens used in this experiment were cylindrical, $10 \mathrm{~mm}$ in length and $11 \mathrm{~mm}$ in diameter. Electrolytic iron with the chemical composition listed in Table 1 was used.

The specimens were first annealed under a vacuum of $1.3332 \times 10^{-3} \mathrm{~Pa}$ at $1250^{\circ} \mathrm{C}$ for $24 \mathrm{~h}$, to have the grain size of about $0.8 \mathrm{~mm}$. The parallel sides of specimens were then carefully cleaned through light pickling. The radioactive tracer ${ }^{64} \mathrm{Cu}$ was subsequently chemically plated onto the flat faces of the specimens from a solution of chloride containing both radioactive and innert copper ions. The final thickness of thin layers containing ${ }^{64} \mathrm{Cu}$ was about $0.5 \mu \mathrm{m}$, and more than $5 \times 10^{5}$ counts per minute were recorded for all of the specimens. The specimens thus plated with ${ }^{64} \mathrm{Cu}$ were sealed in quartz amples under a

Table 1 Chemical composition of specimen (wt \%).

\begin{tabular}{cccccc}
\hline $\mathrm{C}$ & $\mathrm{Mn}$ & $\mathrm{Si}$ & $\mathrm{P}$ & $\mathrm{S}$ & $\mathrm{Cu}$ \\
0.0035 & 0.0050 & 0.0041 & 0.0011 & 0.0062 & 0.0015 \\
\hline $\mathrm{Ni}$ & $\mathrm{Cr}$ & $\mathrm{Al}$ & $\mathrm{O}$ & $\mathrm{N}$ & $\mathrm{Fe}$ \\
0.0013 & 0.0017 & 0.0120 & 0.0036 & 0.0020 & rest \\
\hline
\end{tabular}

1978 Vol. 19 


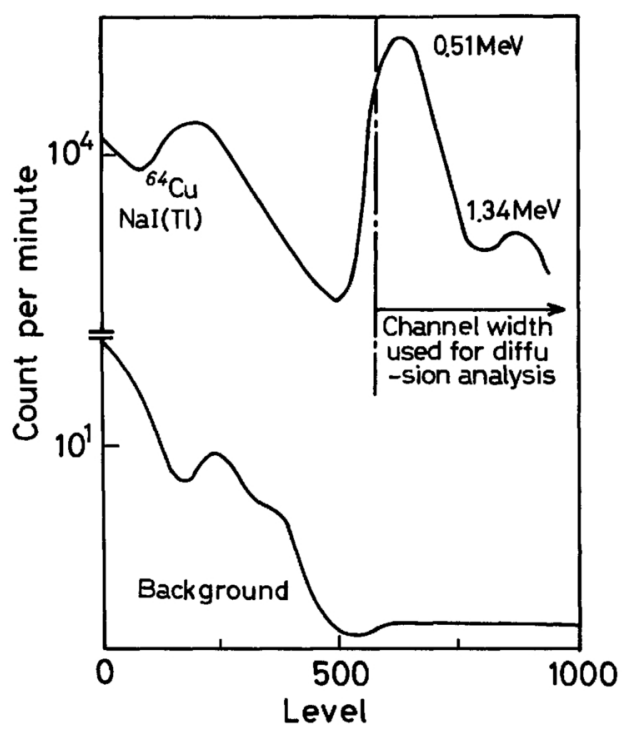

Fig. 1 Energy spectrum of $\gamma$-ray from ${ }^{64} \mathrm{Cu}$.

vacuum of $1.3332 \times 10^{-3} \mathrm{~Pa}$, and diffusionannealed in the temperature range from 1105 to $1210^{\circ} \mathrm{C}$ in furnaces controlled within $\pm 1^{\circ} \mathrm{C}$. After the diffusion anneal, the sample diameters were decreased about $1 \mathrm{~mm}$ on a precision lath, and the diffusion coefficients were determined by the residual-activity technique, where activity measurements were made on the disc specimen after the removal of successive layers of 5-10 $\mu \mathrm{m}$ from the surface, in a well-type scintillation counter. Figure 1 shows the energy spectrum of $\gamma$-ray from ${ }^{64} \mathrm{Cu}$. The activity was measured by counting the 0.51 and $1.34 \mathrm{MeV} \gamma$ radiations of ${ }^{64} \mathrm{Cu}$, and the correction for the decay of ${ }^{64} \mathrm{Cu}$ was done by using the half-time value of ${ }^{64} \mathrm{Cu}(12.8 \mathrm{~h})$ during subsequent counting.

\section{Experimental Results}

When the infinnitesimally thin layer of isotope deposited onto semi-infinitive specimen was diffusion-annealed, the integral activity $\left(I_{n}\right)$ is given by

$$
I_{n}=\int_{-x_{n}}^{\infty} \exp \left\{-\mu\left(x-x_{n}\right)\right\} \cdot \mathrm{d} x,
$$

where $I_{n}$ is the integral activity in units of cpm, $\mu$ is the linear absorption coefficient from the radiation by iron, and $x_{n}$ is the distance from the initial surface to the surface being counted.
Therefore the activity concentration at point $x_{n}$ from the initial surface is given by

$$
\mu I_{n}-\mathrm{d} I_{n} / \mathrm{d} x_{n}=K \cdot C(x) .
$$

In this experiment, $\mu I_{n}$ is negligibly small for the value of $\left(-\mathrm{d} I_{n} / \mathrm{d} x_{n}\right)$, where it is obvious from eq. (2) that the activity concentration is proportional to the term $\left(-\mathrm{d} I_{n} / \mathrm{d} x_{n}\right)$, and the penetration curve necessary for analysing by the instantaneous source model of grain boundary diffusion proposed by Suzuoka is given by plotting the logarithm of activity concentration against the $6 / 5$ power of the depth.

Figure 2(a) shows the typical penetration curve of ${ }^{64} \mathrm{Cu}$ into $\gamma-\mathrm{Fe}$ for the specimen

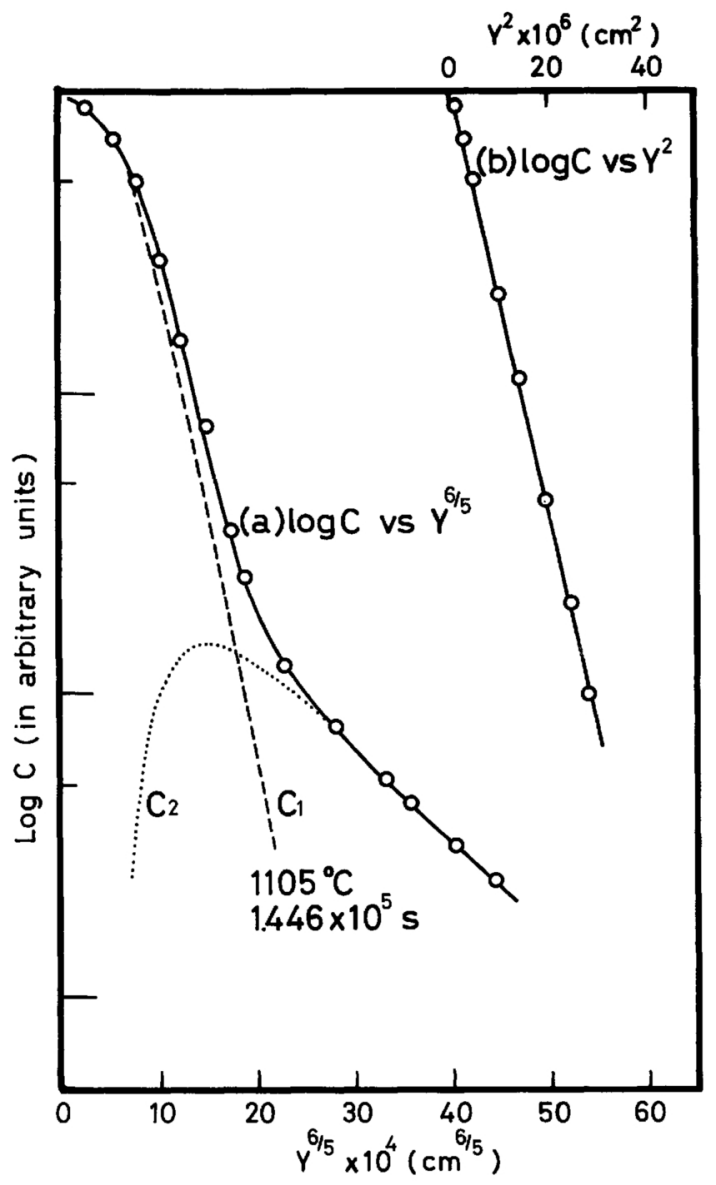

Fig. 2 Typical penetration curve of $\mathrm{Cu}$ into $\gamma$-Fe. Broken line represents volume diffusion term $C_{1}$ and the dotted line represents boundary diffusion term $C_{2}$. 
diffusion-annealed at $1105^{\circ} \mathrm{C}$ for $1.446 \times 10^{5} \mathrm{~s}$, analysed by the above-mentioned procedure. The linear part of this penetration curve represents the pure contribution of grain boundary diffusion, and its slope- $\gamma$ follows the following relation:

$$
\begin{aligned}
& 0.973 \log (\Delta-1) \\
& \quad=6.567-1.644 \log \gamma-\log \sqrt{D_{\ell} \cdot t},
\end{aligned}
$$

where $\Delta$ is $D_{g \cdot b} / D_{\ell}$. According to the eq. (3), it is obvious that $D_{g \cdot b}$ is easily obtained where $D_{\ell}$ is known. However, the reliable value of $D_{\ell}$ for the $\mathrm{Cu}$ into $\gamma-\mathrm{Fe}$ has not yet been reported. Therefore, in this experiment, we used the selfconsistent method which allowed us to make the simultaneous determination of $D_{\ell}$ and $D_{g \cdot b}$, in which the observed values are analysed by the relation

$$
C_{\text {obs }}=K\left(C_{1}+1 / n C_{2}\right),
$$

where $K$ is constant, $n=b / \sqrt{D_{\ell} \cdot t}$, and $2 b$ is the mean linear grain size.

At first, assuming the value of $D_{\ell}$, we separate the term $C_{2}$ of grain boundary dif-

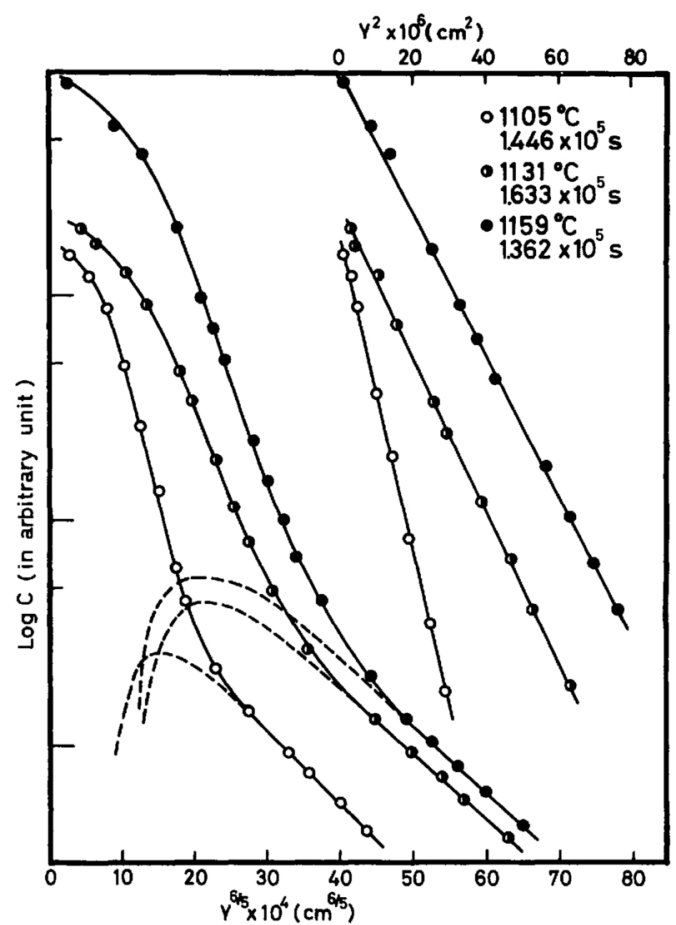

Fig. 3 Penetration curves of $\mathrm{Cu}$ in $\mathrm{Fe}$ and lattice diffusion separated from grain boundary diffusion. fusion from the observed value according to eq. (3), and plot the term of lattice diffusion against $y^{2}$ as shown in Fig. 2(b), from the slope of which the value of $D_{\ell}$ can be obtained. This procedure is repeated until the assumed value of $D_{\ell}$ coincides with the calculated value of $D_{\ell}$.

Figures 3 and 4 show the penetration curves and the lattice diffusion part $C_{\ell}$ separated by the above-mentioned procedure for all of the specimens, where $C_{\ell}-y^{2}$ curves are satisfactorily linear. The values of $D_{\ell}, D_{g \cdot b}$ band other parameters obtained through the analysis by a self-consistent method, are listed in Table 2, where $\beta=\delta(\Delta-1) / \sqrt{D_{\ell} \cdot t}$, and $\delta$ is the thickness of grain boundary, the value of which is $5 \times$ $10^{-8} \mathrm{~cm}$ according to Fisher ${ }^{(12)}$.

The temperature dependences of $D_{\ell}$ and $D_{g \cdot b}$ obtained in this experiment, are presented by black dots in Figs. 5 and 6, both of which are found to be in Arrhenius' relation, and the least squares calculation gives the relation (5) for the lattice diffusion coefficient, and the

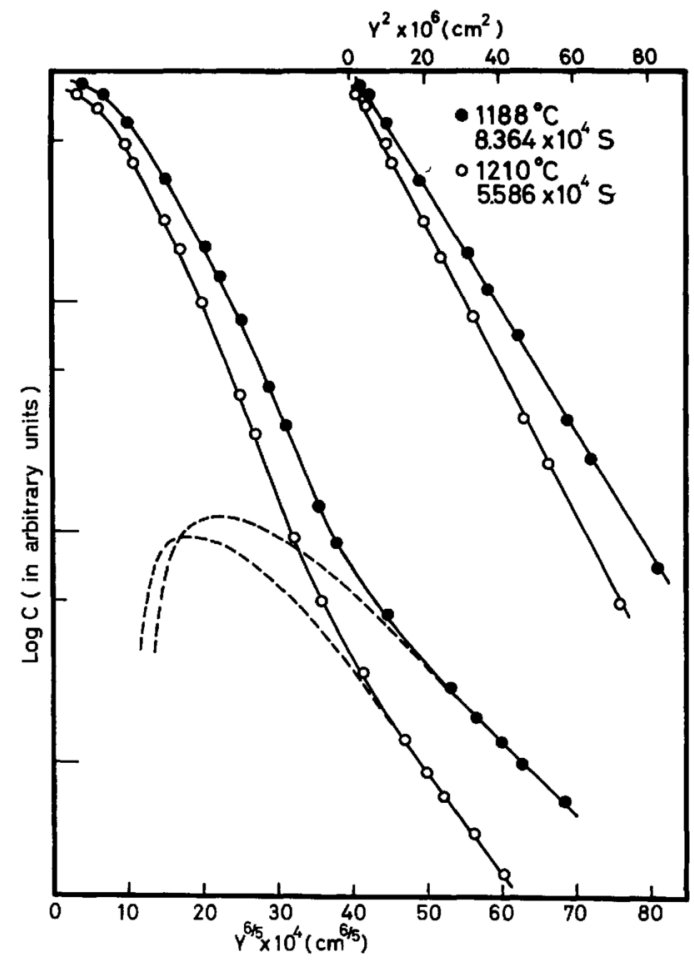

Fig. 4 Penetration curves of $\mathrm{Cu}$ in $\mathrm{Fe}$ and lattice diffusion separated from grain boundary diffusion. 
Table 2 Grain boundary diffusion coefficients and other parameters of $\mathrm{Cu}$ in $\gamma$-Fe.

\begin{tabular}{lccccc}
\hline \multicolumn{1}{c}{ Specimen No. } & 1 & 2 & 3 & 4 & 5 \\
\hline$T\left({ }^{\circ} \mathrm{C}\right)$ & 1210 & 1188 & 1159 & 1131 & 1105 \\
$1 / T \times 10^{4}\left(\mathrm{~K}^{-1}\right)$ & 6.7431 & 6.8446 & 6.9832 & 7.1225 & 7.2569 \\
$t \times 10^{-5}(\mathrm{~s})$ & 0.4475 & 0.8364 & 1.177 & 1.633 & 1.446 \\
$D_{\ell} \times 10^{15}\left(\mathrm{~m}^{2} / \mathrm{s}\right)$ & 7.64 & 4.97 & 2.94 & 2.01 & 1.09 \\
$\left(D_{\ell} \cdot t\right)^{1 / 2} \times 10^{5}(\mathrm{~m})$ & 1.85 & 2.04 & 1.86 & 1.81 & 1.26 \\
$\gamma \times 10^{-2}$ & 4.20 & 3.38 & 3.05 & 2.99 & 3.08 \\
$\Delta \times 10^{5}$ & 1.34 & 1.74 & 2.28 & 2.42 & 3.36 \\
$D_{b} \cdot \delta \times 10^{19}\left(\mathrm{~m}^{3} / \mathrm{s}\right)$ & 5.10 & 4.33 & 3.35 & 2.43 & 1.83 \\
$\beta$ & 3.61 & 4.28 & 6.13 & 6.69 & 13.38 \\
$n \quad$ Effective grain size & 25.2 & 25.8 & 58.6 & 18.3 & 24.8 \\
\multicolumn{1}{r}{} & 0.93 & 1.05 & 2.18 & 0.66 & 0.62 \\
\hline \hline
\end{tabular}

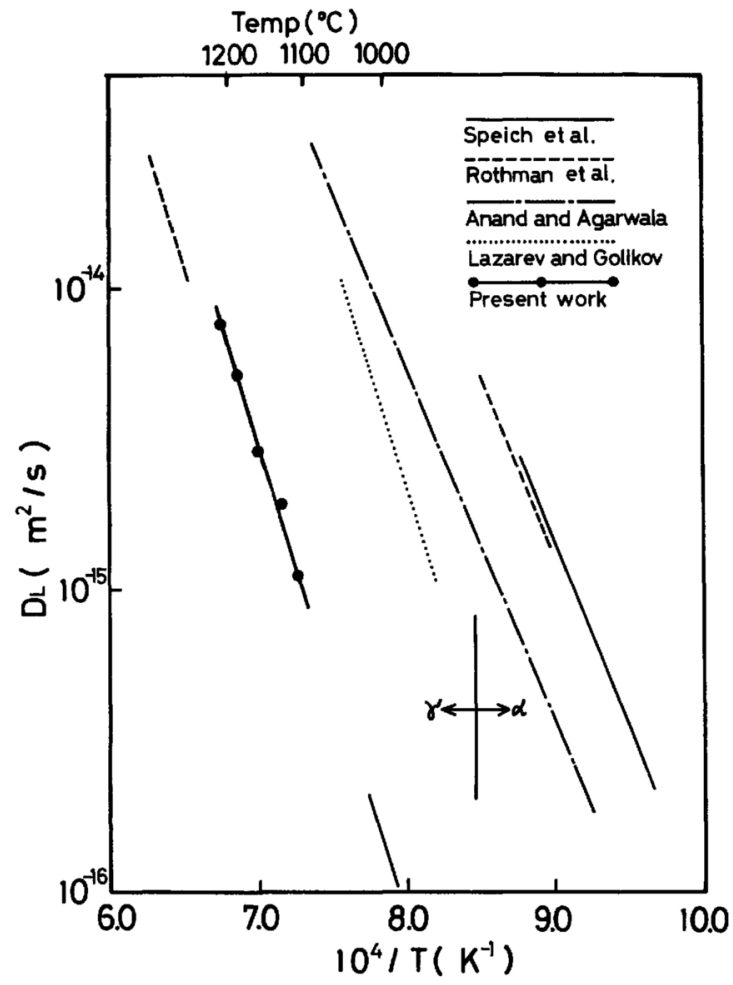

Fig. 5 Temperature dependence of $D_{l}$ of ${ }^{64} \mathrm{Cu}$ in $\mathrm{Fe}$.

relation (6) for the grain boundary diffusion coefficient, respectively.

$$
\begin{aligned}
D_{\ell}= & 4.16 \times 10^{-4} \\
& \times \exp \left(-305.0 \mathrm{~kJ} \cdot \mathrm{mol}^{-1} / R T\right) \mathrm{m}^{2} \mathrm{~s}^{-1}, \\
D_{g \cdot b} \cdot \delta= & 4.27 \times 10^{-13} \\
& \times \exp \left(-167.8 \mathrm{~kJ} \cdot \mathrm{mol}^{-1} / R T\right) \mathrm{m}^{3} \mathrm{~s}^{-1},
\end{aligned}
$$

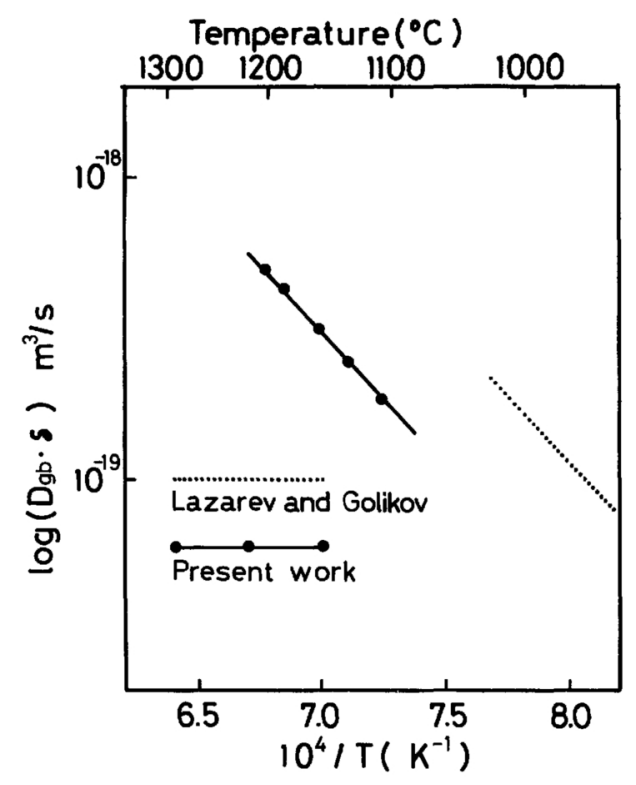

Fig. 6 Temperature dependence of $D_{b} \cdot \delta$ of ${ }^{64} \mathrm{Cu}$ in $\mathrm{Fe}$.

\section{Discussion}

The solid lines in Fig. 5 show the data of Speich et al. ${ }^{(4)}$ concerning with the lattice diffusion coefficient obtained by a microprobe analysis using the iron specimen plated with innert copper, and their data is reliable.

Anand and Agarwala ${ }^{(3)}$, using the residual activity technique, measured the lattice diffusion coefficient of ${ }^{64} \mathrm{Cu}$ into iron in the temperature range from 800 to $1050^{\circ} \mathrm{C}$. However, they did not find any discontinuity at the $\alpha \rightarrow \gamma$ transformation temperature in the Arrhenius plot of $D_{\ell}$, and their values of $D_{\ell}$ were some- 
Table 3 Published data on diffusion of $\mathrm{Cu}$ in $\mathrm{Fe}$.

\begin{tabular}{cccl}
\hline $\begin{array}{c}D_{0} \times 10^{4} \\
\left(\mathrm{~m}^{2} / \mathrm{s}\right)\end{array}$ & $\begin{array}{c}Q \\
(\mathrm{~kJ} / \mathrm{mol})\end{array}$ & $\begin{array}{c}\text { Temperature } \\
\text { range }\left({ }^{\circ} \mathrm{C}\right)\end{array}$ & Worker \\
\hline 3.0 & 255.2 & $800-1200$ & Linder and Karnik \\
0.57 & 238.5 & $800-1050$ & Anand and Agarwala \\
1.8 & 295.0 & $910-1020$ & Speich et al. \\
2.86 & 306.7 & $1285-1368$ & Rothman et al. \\
92 & 301.3 & $910-1050$ & Lazarev and Golikov \\
4.16 & 305.0 & $1105-1210$ & Present work \\
\hline \hline
\end{tabular}

Table 4 Published data on grain boundary diffusion of $\mathrm{Cu}$ in $\mathrm{Fe}$.

\begin{tabular}{cccl}
\hline $\begin{array}{c}\delta \cdot D_{0} \\
\left(\mathrm{~m}^{3} \cdot \mathrm{s}\right)\end{array}$ & $\begin{array}{c}Q \\
(\mathrm{~kJ} / \mathrm{mol})\end{array}$ & $\begin{array}{c}\text { Temperature } \\
\text { range }\left({ }^{\circ} \mathrm{C}\right)\end{array}$ & Worker \\
\hline $4.0 \times 10^{-12}$ & 181.6 & $677-722$ & Bergh \\
$13.0 \times 10^{-12}$ & 159.0 & $707-870$ & Lazarev and Golikov \\
$3.2 \times 10^{-12}$ & 177.8 & $910-1050$ & Lazarev and Golikov \\
$4.27 \times 10^{-13}$ & 167.8 & $1105-1210$ & Present work \\
\hline \hline
\end{tabular}

what higher than those of Speich et al., in the $\gamma$ region.

In determining the lattice diffusion of $\mathrm{Cu}$ into iron, Rothman et al. $^{(8)}$ at first examined the temperature range where the grain boundary diffusion was predominant, and found that the grain boundary diffusion was predominant at temperatures lower than $815^{\circ} \mathrm{C}$ in the $\alpha$ region, and at temperatures lower than $1250^{\circ} \mathrm{C}$ in the $\gamma$ region. Therefore the data of Rothman et al., shown in Fig. 5, are concerned with the lattice diffusion coefficients obtained in the temperature range where the contribution of grain boundary diffusion is negligible, and their data are in good agreement with Speich et al. However, they only suggested that the grain boundary diffusion was dominant in the $\gamma$ region lower than $1250^{\circ} \mathrm{C}$, and did not determine the value of $D_{\ell}$ separated from grain boundary diffusion.

Lazarev and Golikov ${ }^{(6)}$ measured the value of $D_{\ell}$ separated from $D_{g \cdot b}$ in the $\gamma$ region from 910 to $1050^{\circ} \mathrm{C}$ lower than the $\mathrm{Cu}$ melting point of $1083^{\circ} \mathrm{C}$ and their values of $D_{\ell}$ are higher than those of Speich et al. and Rothman et al.

In this experiment, we determined the values of lattice diffusion coefficient and grain boundary diffusion coefficient simultaneously, in the temperature range between 1105 and $1210^{\circ} \mathrm{C}$. The data is necessary for the sintering of $\mathrm{Fe}-\mathrm{Cu}$ binary mixed powder compacts. The temperature dependence of $D_{\ell}$ is represented by a straight line as shown in Fig. 5, indicating also that our data is in good accord with those reported by Speich et al. and Rothman et al. As shown in Table 3, there are no marked differences in activation energy: $295.0 \mathrm{~kJ}$. $\mathrm{mol}^{-1}$ by Speich et al., $306.7 \mathrm{~kJ} \cdot \mathrm{mol}^{-1}$ by Rothman et al., and $305.0 \mathrm{~kJ} \cdot \mathrm{mol}^{-1}$ in this experiment.

No reports have yet been reported on the grain boundary diffusion coefficient in the temperature range higher than $1083^{\circ} \mathrm{C}$. There is only one report by Lazarev et al. in the temperature range between 910 and $1050^{\circ} \mathrm{C}$. The temperature dependence of grain boundary diffusion coefficient obtained in this experiment is represented by a solid line as shown in Fig. 6, and the activation energy calculated from the slope of it is $167.8 \mathrm{~kJ} \cdot \mathrm{mol}^{-1}$ as shown in Table 4. It has been confirmed by James and Leak $^{(13)}$ that the ratio of the activation energy necessary for the grain boundary diffusion against that for the lattice diffusion coefficient is 0.53 . Therefore the value $\left(Q_{g \cdot b} / Q_{\ell}\right)$ of 0.55 obtained in this experiment is reasonable.

\section{Conclusion}

The temperature dependences of the volume diffusion coefficient and the grain boundary 
diffusion coefficient are given by

$$
\begin{gathered}
D_{\ell}=4.16 \times 10^{-4} \\
\times \exp \left(-305.0 \mathrm{~kJ} \cdot \mathrm{mol}^{-1} / R T\right) \mathrm{m}^{2} \mathrm{~s}^{-1}, \\
\begin{aligned}
& D_{g \cdot b} \cdot \delta= 4.27 \times 10^{-13} \\
& \times \exp \left(-167.8 \mathrm{~kJ} \cdot \mathrm{mol}^{-1} / R T\right) \mathrm{m}^{3} \mathrm{~s}^{-1} . \\
& \text { REFERENCES }
\end{aligned}
\end{gathered}
$$

\section{REFERENCES}

(1) For example, H. Mitani, K. Majima and Y. Hanatate: J. Japan Inst. Metals, 25 (1961), 639.

(2) R. Linder and F. Karnik: Acta Met., 3 (1955), 297.

(3) M. S. Anand and R. P. Agarwala: J. Appl. Phys., 37 (1966), 4248.
(4) G. R. Speich, J. A. Gula and R. M. Fisher: The Electron Microprobe, John Wiley \& Sons, Inc., New York, (1966), 525.

(5) V. A. Lazarev and V. M. Golikov: Fiz. Metal. Metalloved, 29 (1970), 154.

(6) V. A. Lazarev and V. M. Golikov: Fiz. Metal. Metalloved, 31 (1971), 885.

(7) Sigge Bergh: Jernkont. Ann., 155 (1971),143.

(8) S. J. Rothman, N. L. Peterson, C. M. Walter and L. T. Nowicki: J. Appl. Phys., 39 (1968), 5041.

(9) T. Suzuoka: Trans. JIM, 2 (1961), 25.

(10) T. Suzuoka: Trans. JIM, 2 (1961), 176.

(11) T. Suzuoka: J. Phys. Soc. Japan, 19 (1964), 839.

(12) J. C. Fisher: J. Appl. Phys., 22 (1951), 74.

(13) D. W. James and G. M. Leak: Phil. Mag., 12 (1965), 491. 